\title{
Questionnaire-based approach to assess schoolchildren's physical fitness and its potential role in exploring the putative impact of helminth and Plasmodium spp. infections in Côte d'Ivoire
}

Thomas Fürst ${ }^{1,2^{*}}$, Ivan Müller ${ }^{1,3,4}$, Jean T Coulibaly ${ }^{1,2,4,5}$, Adrien K Yao ${ }^{6}$, Jürg Utzinger ${ }^{1,2}$ and Eliézer K N'Goran ${ }^{4,5}$

\begin{abstract}
Background: Disability weights (DWs) are important for estimating burden of disease in terms of disabilityadjusted life years. The previous practice of eliciting DWs by expert opinion has been challenged. More recent approaches employed quality of life (QoL) questionnaires to establish patient-based DWs, but results are ambiguous.
\end{abstract}

Methods: In early 2010, we administered a questionnaire pertaining to physical fitness to 200 schoolchildren in Côte d'Ivoire. Helminth and Plasmodium spp. infections were determined and schoolchildren's physical fitness objectively measured in a maximal multistage $20 \mathrm{~m}$ shuttle run test. Associations between objectively measured and self-reported physical fitness and between self-reported physical fitness and infection status were determined. Spearman rank correlation coefficient, uni- and multivariable linear regression models adjusting for children's age and sex, ambient air temperature and humidity, Fisher's test, $\chi^{2}$ and t-test statistics were used for statistical analysis.

Results: The prevalence of Schistosoma haematobium, Plasmodium spp., Schistosoma mansoni, hookworm and Ascaris lumbricoides in 167 children with complete parasitological results was $84.4 \%, 74.9 \%, 54.5 \%, 14.4 \%$ and $1.2 \%$, respectively. High infection intensities and multiple species parasite infections were common. In the 137 children with complete data also from the shuttle run test, we found statistically significant correlations between objectively measured and self-reported physical fitness. However, no statistically significant correlation between the children's parasitic infection status and self-reported physical fitness was identified. An attrition analysis revealed considerably lower self-reported physical fitness scores of parasitized children who were excluded from shuttle run testing due to medical concerns in comparison to parasitized children who were able to successfully complete the shuttle run test.

Conclusions: Our QoL questionnaire proofed valid to assess children's physical fitness in the current study area. Reasons why no differences in self-reported physical fitness in children with different parasitic infections were found are manifold, but do not preclude the use of QoL questionnaires in the elicitation of DWs. Indeed, the questionnaire was particularly useful in assessing physical fitness of those children, who were - supposedly due to parasitic infections - unable to complete the shuttle run test. Hence, we encourage others to use QoL questionnaires to determine not only physical fitness, but also more subtle morbidities.

\footnotetext{
* Correspondence: thomas.fuerst@unibas.ch

'Department of Epidemiology and Public Health, Swiss Tropical and Public

Health Institute, Basel, Switzerland

Full list of author information is available at the end of the article
} 


\section{Background}

The current revision of the Global Burden of Diseases, Injuries and Risk Factors (GBD) 2010 study has sparked new interest in quantifying disability attributable to all kinds of diseases, injuries and risk factors [1]. A crucial variable to estimate the GBD in terms of disabilityadjusted life years (DALYs) is the disability weight (DW); a measure which ranges between 0 (perfect health) and 1 (death). Indeed, DWs should capture the disability incurred by an average case suffering from a specific sequela [2]. Of note, DWs are complementary to the utility weights used in the earlier but related qualityadjusted life years (QALYs) metrics $[3,4]$. In the initial GBD 1990 study, DWs were assessed by person trade-off exercises assigned to panels of public health experts [2]. This dependence on theoretical contemplation was one important source of criticism on the DALY metrics [4-7]. Hence, different research groups started to use one of the growing number of quality of life (QoL) questionnaire tools to estimate patient-based proxies for DWs for a wide range of health impairments [8] - amongst them the often subtle and therefore particularly difficult to elicit morbidity caused by neglected tropical diseases (NTDs). While some results indicate that QoL is significantly lower among individuals affected by NTDs compared to their non-affected counterparts $[9,10]$, others do not [11]. These conflicting findings might reflect the early state of research investigating the relationship between QoL and NTDs, and hence the need for further scientific inquiry has been emphasised [12,13]. However, the ambiguity of this early research also raises questions about the reliability and validity of a questionnaire-based approach in the assessment of impairments in QoL due to NTDs.

We used data from a cross-sectional survey pertaining to schoolchildren's helminth and Plasmodium spp. infections, as determined by standardised, quality-controlled parasitological methods. The data were juxtaposed to children's physical fitness, as objectively measured in a maximal multistage $20 \mathrm{~m}$ shuttle run test. Additionally, children's self-reported physical fitness was obtained by means of a QoL questionnaire. We determined associations between objectively measured and self-reported physical fitness on one hand, and self-reported physical fitness and infection status on the other hand. Particular emphasis was placed on physical fitness as it is a crucial dimension of QoL. Indeed, physical fitness is included in all generic QoL questionnaires [14-16] and, in our view, the dimension of QoL that can be most easily assessed objectively. We present an evaluation of a QoL questionnaire focusing on the dimension of physical activity. This tool was embedded in a cross-sectional epidemiological survey, which aimed at assessing the effect of helminth and Plasmodium spp. infections on schoolchildren's physical fitness in a rural setting of southern Côte d'Ivoire [17].

\section{Methods}

\section{Study area and data collection}

In early 2010, we invited all 204 schoolchildren attending grades 4-6 of Grand Moutcho primary school in Agboville, south Côte d'Ivoire, to participate in a cross-sectional epidemiological survey. In a first step, district health and education authorities, village leaders and teachers were informed about the purpose, procedures and potential risks of the study. After obtaining their oral agreement, written informed consent was sought from the parents or legal guardians of the children, whereas children assented orally.

In a next step, children were asked to fill out a brief questionnaire, assisted by their class teachers if needed. The questionnaire was based on two sections about physical functioning (PF) and physical role (PR) from the most widely used generic SF-36v2 questionnaire (Medical Outcome Trust, Boston, MA, USA; Health Assessment Lab, Boston, MA, USA; QualityMetric, Lincoln, RI, USA) $[8,14,18]$. Fourteen questions were included and readily adapted to the specific study setting. The questionnaire was pre-tested with support of the head of the school and further revised (see Additional file 1: Questionnaire used to assess self-reported physical fitness in the present study; in French).

Next, participating children were given plastic containers and invited to submit, on the next day, a small portion of their fresh morning stool. After stool collection, from 10:00 hours onwards, children were given a second plastic container and asked to bring a urine sample by 14:00 hours the latest. This procedure was repeated over two consecutive days. Stool and urine samples were transferred to the nearby hospital laboratory of the district town Agboville. Duplicate Kato-Katz thick smears were prepared from each of the two stool samples and quantitatively examined by experienced laboratory technicians for eggs of Schistosoma mansoni and soil-transmitted helminths (i.e. Ascaris lumbricoides, hookworm and Trichuris trichiura) on the same day [19]. Urine samples were subjected to the filtration method and the number of Schistosoma haematobium eggs in a filtrate of $10 \mathrm{ml}$ of urine counted under a microscope [20,21]. Ten percent of all parasitological results were re-examined by a senior technician for quality control. In case of disagreement with initial findings, the results were discussed with the respective technician and the corresponding sample reanalysed until agreement was reached.

After the helminthological screening, children were clinically examined by a physician to check their general state of health. Additionally, a rapid diagnostic test 
(RDT) for malaria was performed (ICT ML01 malaria Pf kit, ICT Diagnostics; Cape Town, South Africa). Children with clinical malaria (defined as positive RDT plus recent history of fever), asthma (assessed by stethoscopy), anaemia (assessed by observing conjunctival vasculature [22]) or dyspnoea (assessed by stethoscopy), according to the physician's appraisal, were excluded from the subsequent fitness test, as participation was considered potentially harmful to them.

Finally, all remaining children were invited to participate in a maximal multistage $20 \mathrm{~m}$ shuttle run test to assess the cumulatively covered distance and the aerobe capacity, as measured by their maximal oxygen uptake, the so-called $\mathrm{VO}_{2} \max$ (expressed in $\mathrm{ml} \mathrm{kg}^{-1} \min ^{-1}$ ) $[23,24]$. The shuttle run test was conducted in groups of not more than 10 children. The obtained results were used as objectively determined proxies for the children's physical fitness. To ensure that children really tried to reach their maximal physical capacity, their heart rate was observed with a Polar RS400 watch (Polar Electro Europe BV; Zug, Switzerland) and only results of children with more than 180 heart beats per min were considered valid. Throughout the shuttle run test, we monitored ambient air temperature and humidity, as these external factors might influence children's test performance.

\section{Ethical approval}

The study was approved by the institutional research commission of the Swiss Tropical and Public Health Institute (Basel, Switzerland) and received clearance from the ethics committees of Basel (EKBB, reference no. 377/09) and Côte d'Ivoire (reference no. 1993 MSHP/CNER). Insurance coverage was obtained from GNA Assurance (Abidjan, Côte d'Ivoire; policy no. 30105811010001).

At the end of the study, all children attending Grand Moutcho primary school were administered praziquantel (single $40 \mathrm{mg} / \mathrm{kg}$ oral dose) and albendazole (single $400 \mathrm{mg}$ oral dose) free of charge, irrespective of their helminth infection status and whether or not they participated in the study. Children who required further medical treatment were referred to the local health service.

\section{Data analysis}

Data were double-entered and cross-checked in Access version 2007 (Microsoft Corporation; Redmond, WA, USA) and analysed in STATA version 10.1 (STATA Corporation; College Station, TX, USA). Questionnaire answers were coded as 1, 2 or 3 (for some questions also 4) with lower scores given to reports of more problems in a certain activity. The individual scores from questions 1 to 10 and 11 to 14 , respectively (see Additional file 1: Questionnaire used to assess self-reported physical fitness in the present study) were summed up in order to obtain a summary measure on PF (questions 1 to 10 ) and PR (questions 11 to 14). While PF is a summary measure for the ability to fulfil distinct physical tasks (e.g. walking, running and climbing), PR pertains to the physical potential to handle certain (social) roles (e.g. learning, helping and playing). According to this procedure, higher values for PF and $\mathrm{PR}$ indicate fewer problems in the respective domain. In a last step, scores for PF and PR were transformed to values between 0 and 100, according to equation (1) [25]:

$$
\text { transformed score }=\left[\frac{(\text { actual raw score }- \text { lowest possible raw score })}{\text { possible raw score range }}\right] * 100
$$

Helminth infection intensities were classified as light, moderate and heavy, using readily available guidelines from the World Health Organization (WHO) [26]. Children's $\mathrm{VO}_{2}$ max was derived from equation (2), considering age $\left(\mathrm{X}_{1}=\right.$ age in years $)$, the achieved maximal shuttle running speed $\left(\mathrm{X}_{2}=\right.$ speed in $\left.\mathrm{km} / \mathrm{h}\right)$ and a linear relation according to Léger and Mercier [23]:

$V O_{2} \max =31.025-3.248 * X_{1}+3.238 * X_{2}+0.154 * X_{1} * X_{2}$

Two different samples were considered in the final analysis in order to assess also the value added by a QoL questionnaire. Sample 1 consisted of all children with complete questionnaire, parasitological and clinical data records. Sample 2 included all children from sample 1 who had not only complete questionnaire, parasitological and clinical data, but also valid physical fitness test results. An attrition analysis was carried out with those children who were included in sample 1 , but not in sample 2, i.e. who had complete data records except for the physical fitness test. Besides descriptive statistics, Spearman rank correlation coefficient, uni- and multivariable linear regression models adjusted for participants' age and sex, ambient air temperature and humidity, Fisher's test, $\chi^{2}$ and t-test statistics were employed as appropriate to assess statistical significance $(\mathrm{p}<0.05)$.

\section{Results}

\section{Operational results}

Operational results of the study are summarised in Figure 1. The two final study samples consisted of 167 children (97 boys and 70 girls) and 137 children (79 boys and 58 girls), both with a mean age of 12.0 years (range: 7-15 years). No statistically significant differences in terms of children's sex and age was identified between the two samples ( $\mathrm{p}>0.05$ ). The 30 children (18 boys and 12 girls) who were part of sample 1 but excluded from sample 2 due to incomplete physical fitness test data had a mean age of 11.8 years (range: 814 years). Reasons for having no valid physical fitness test data were the exclusion from the shuttle run test 


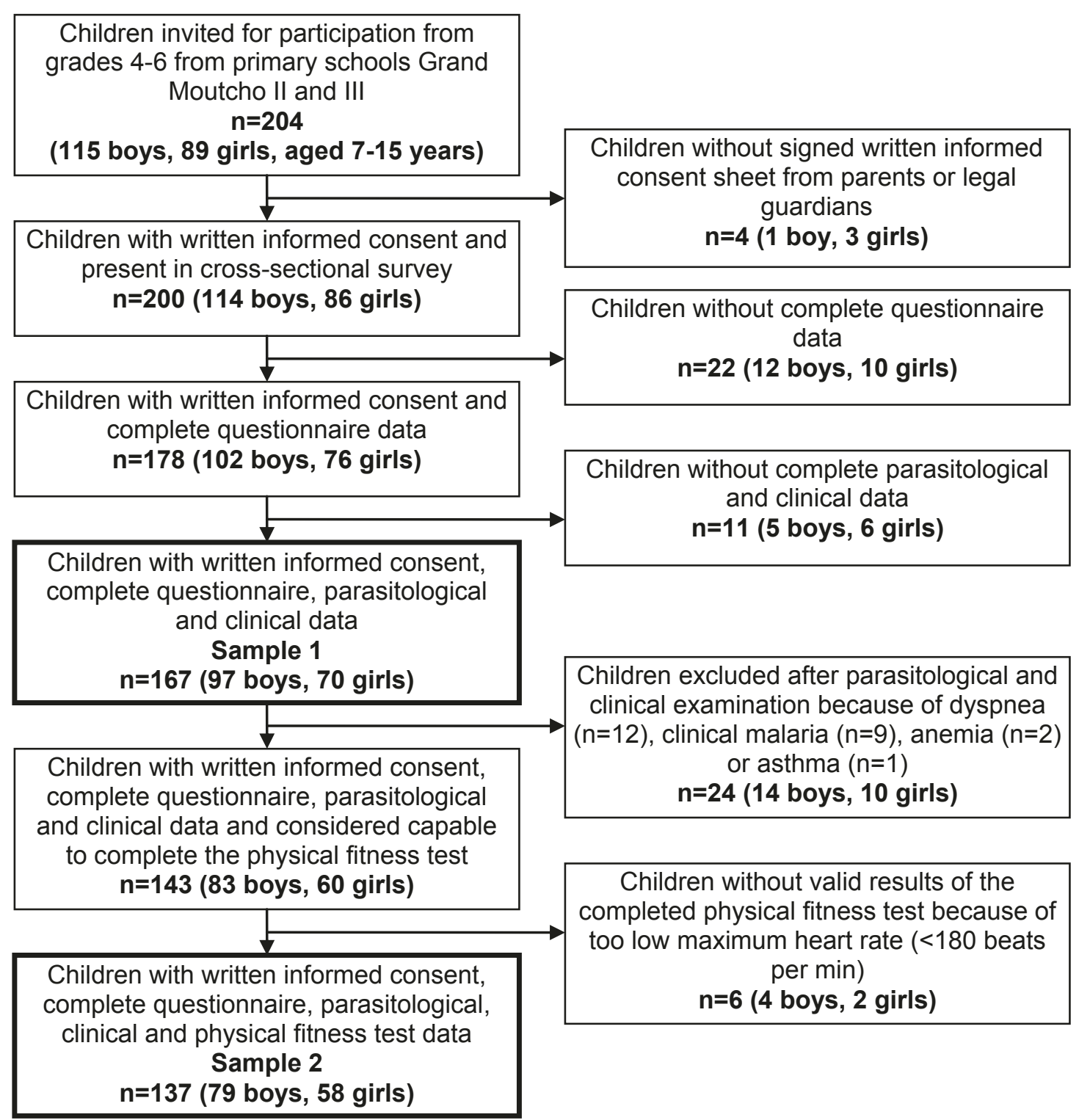

Figure 1 Flow chart detailing operational study results and the two different samples further considered in the analysis. The study was carried out in Grand Moutcho school, Agboville, Côte d'Ivoire, in early 2010.

due to medical concerns (i.e. dyspnea $(\mathrm{n}=12)$, clinical malaria $(\mathrm{n}=9)$, anemia $(\mathrm{n}=2)$ and asthma $(\mathrm{n}=1))$ or reaching too low maximum heart rate $(<180$ beats per $\min )$ in the shuttle run test $(\mathrm{n}=6)$.

\section{Parasitological results}

Tables 1 and 2 summarise the parasitological results. The prevalence of S. haematobium, Plasmodium spp., S. mansoni, hookworm and $A$. lumbricoides in the 167 children with complete parasitological results was $84.4 \%, 74.9 \%$, $54.5 \%, 14.4 \%$ and $1.2 \%$, respectively. No T. trichiura infection was diagnosed. High intensity helminth infections were common and only $10.8 \%$ of all children were completely helminth-free, while $32.9 \%$ harboured a single and $56.3 \%$ two or more helminth species concurrently. No significant differences in helminth prevalences, infection intensities or helminth co-infections were found between sample 1 and sample $2(\mathrm{p}>0.05)$.

Results of the questionnaire survey and shuttle run test Mean scores for PF were 51.3 (95\% confidence interval (CI): 48.9-53.6) and 52.2 (95\% CI: 49.8-54.7) in samples 1 and 2, respectively (Table 3 ). Mean scores for PR equalled 50.4 (95\% CI: 46.7-54.0) and 51.3 (95\% CI: 47.3-55.4). Means of the two objectively measured outcome variables, namely cumulative distance covered by 
Table 1 Parasitic infections and infection intensities in the two samples analysed

\begin{tabular}{|c|c|c|c|c|c|c|c|}
\hline \multirow[b]{2}{*}{ Parasite } & \multirow[b]{2}{*}{ Infection } & \multicolumn{3}{|c|}{ Sample 1} & \multicolumn{3}{|c|}{ Sample 2} \\
\hline & & Male & Female & Total & Male & Female & Total \\
\hline \multirow[t]{3}{*}{ S. haematobium } & no & 18 & 8 & 26 & 14 & 7 & 21 \\
\hline & light (1-49 eggs/10 ml urine) & 46 & 35 & 81 & 38 & 27 & 65 \\
\hline & heavy ( $\geq 50$ eggs/10 $\mathrm{ml}$ urine) & 33 & 27 & 60 & 27 & 24 & 51 \\
\hline \multirow[t]{4}{*}{ S. mansoni } & no & 52 & 24 & 76 & 42 & 19 & 61 \\
\hline & light (1-99 EPG $\left.{ }^{\mathrm{a}}\right)$ & 31 & 26 & 57 & 26 & 23 & 49 \\
\hline & moderate (100-399 EPG $\left.{ }^{a}\right)$ & 12 & 19 & 31 & 10 & 15 & 25 \\
\hline & heavy $\left(\geq 400 \mathrm{EPG}^{\mathrm{a}}\right)$ & 2 & 1 & 3 & 1 & 1 & 2 \\
\hline \multirow[t]{3}{*}{ A. lumbricoides } & no & 96 & 69 & 165 & 78 & 57 & 135 \\
\hline & light (1-4999 EPG $)$ & 1 & 0 & 1 & 1 & 0 & 1 \\
\hline & moderate $\left(5,000-49,999\right.$ EPG $\left.{ }^{\mathrm{a}}\right)$ & 0 & 1 & 1 & 0 & 1 & 1 \\
\hline \multirow[t]{3}{*}{ Hookworm } & no & 78 & 65 & 143 & 64 & 53 & 117 \\
\hline & light (1-1,999 EPG $)$ & 18 & 5 & 23 & 15 & 5 & 20 \\
\hline & moderate $\left(2,000-3,999 \mathrm{EPG}^{\mathrm{a}}\right)$ & 1 & 0 & 1 & 0 & 0 & 0 \\
\hline \multirow[t]{2}{*}{ Plasmodium spp. } & no & 24 & 18 & 42 & 23 & 15 & 38 \\
\hline & yes & 73 & 52 & 125 & 56 & 43 & 99 \\
\hline
\end{tabular}

${ }^{\mathrm{a}} \mathrm{EPG}$, eggs per gram of stool

Parasitological data stem from a study carried out in Grand Moutcho school, Agboville, Côte d'Ivoire, in early 2010 [17]. Sample 1 with $n=167$ observations (97 boys, 70 girls) includes all children with complete questionnaire, parasitological and clinical data. Sample 2 with n = 137 observations (79 boys, 58 girls) includes all children from sample 1 who had not only complete questionnaire, parasitological and clinical data, but also valid shuttle run test results (see also Figure 1 ). Infection intensities were defined according to WHO guidelines [26].

the children in the shuttle run test and $\mathrm{VO}_{2} \mathrm{max}$, as measured only in sample 2, were $1,301 \mathrm{~m}(95 \% \mathrm{CI}$ : $1,242-1,360 \mathrm{~m}$ ) and $52.7 \mathrm{ml} \mathrm{kg}{ }^{-1} \mathrm{~min}^{-1}$ (95\% CI: 51.9 $53.5 \mathrm{ml} \mathrm{kg}^{-1} \mathrm{~min}^{-1}$ ), respectively.

Spearman rank correlation coefficients indicated statistically significant and positive correlation between PF and cumulative distance and $\mathrm{VO}_{2} \max$ (Table 4). No such correlation was found between PR and the cumulative distance or $\mathrm{VO}_{2} \max$.

Uni- and multivariable regression models demonstrated statistically significant correlations of PF and sex with cumulative distance and of PF, sex and age with $\mathrm{VO}_{2}$ max (Table 5 ). PR showed no statistically significant association with the cumulative distance or $\mathrm{VO}_{2}$ max.

Despite diverse infection patterns of the children, uniand multivariable regression models revealed no statistically significant correlations between participating schoolchildren's score on PF, which proofed to be valid as predictor for their physical fitness, and their parasitic infection status (Table 6).

\section{Results of the attrition analysis}

An attrition analysis of the group of 30 children excluded in sample 2 showed that this group was neither significantly different in terms of their sex- or age-composition, nor their respective parasite prevalences, infection intensities or levels of multiple helminth species infections ( $p>0.05)$. However, as expected because of their medical complaints, they reported lower PF scores as a group (mean $=46.8 ; 95 \%$ CI: 39.9-53.8). Furthermore, while the three completely parasite-free children achieved considerably higher mean PF scores (mean $=66.7$; 95\% CI: 16.5-116.9), the 27 parasitized children reported lower mean PF scores (mean $=44.6$; 95\% CI: 37.8-51.5) than their peers from sample 2 (Table 7).

Table 2 Helminth co-infections in the two samples analysed

\begin{tabular}{|c|c|c|c|c|c|c|}
\hline \multirow[b]{2}{*}{ Number of concurrent helminth infections } & \multicolumn{3}{|c|}{ Sample 1} & \multicolumn{3}{|c|}{ Sample 2} \\
\hline & Male & Female & Total & Male & Female & Total \\
\hline Zero & 13 & 5 & 18 & 11 & 4 & 15 \\
\hline One & 35 & 20 & 55 & 27 & 16 & 43 \\
\hline Two & 39 & 41 & 80 & 33 & 34 & 67 \\
\hline Three & 9 & 4 & 13 & 7 & 4 & 11 \\
\hline Four & 1 & 0 & 1 & 1 & 0 & 1 \\
\hline
\end{tabular}

Parasitological data stem from a study carried out in Grand Moutcho school, Agboville, Côte d'Ivoire, in early 2010 [17]. Sample 1 with $\mathrm{n}=167$ observations (97 boys, 70 girls) includes all children with complete questionnaire, parasitological and clinical data. Sample 2 with $\mathrm{n}=137$ observations (79 boys, 58 girls) includes all children from sample 1 who had not only complete questionnaire, parasitological and clinical data, but also valid shuttle run test results (see also Figure 1). 
Table 3 Summary of the questionnaire scores and shuttle run test results in the two samples analysed

\begin{tabular}{|c|c|c|c|c|c|c|c|}
\hline \multirow[b]{2}{*}{ Test } & \multirow[b]{2}{*}{ Variable } & \multicolumn{3}{|c|}{ Sample 1} & \multicolumn{3}{|c|}{ Sample 2} \\
\hline & & Male & Female & Total & Male & Female & Total \\
\hline \multirow[t]{2}{*}{ Questionnaire score } & Physical functioning & 53.0 & 48.9 & 51.3 & 53.2 & 50.9 & 52.2 \\
\hline & Physical role & 50.9 & 49.6 & 50.4 & 51.2 & 51.6 & 51.3 \\
\hline \multirow[t]{2}{*}{ Shuttle run test } & Distance & n.a. ${ }^{a}$ & n.a. ${ }^{a}$ & n.a. ${ }^{\text {a }}$ & 1,452 & 1,094 & 1,301 \\
\hline & $\mathrm{VO}_{2} \max$ & n.a. ${ }^{a}$ & n.a. ${ }^{a}$ & п.а. ${ }^{a}$ & 54.5 & 50.3 & 52.7 \\
\hline
\end{tabular}

a n.a., not applicable

Cumulative distance (in $\mathrm{m}$ ) and $\mathrm{VO}_{2} \mathrm{max}$ (in $\mathrm{ml} \mathrm{kg}^{-1} \mathrm{~min}^{-1}$ ) as objectively measured and questionnaire scores on physical functioning and physical role as selfreported variables in samples 1 and 2 from a study carried out in Grand Moutcho school, Agboville, Côte d'Ivoire, in early 2010 [17]. Sample 1 with $n=167$ observations ( 97 boys, 70 girls) includes all children with complete questionnaire, parasitological and clinical data. Sample 2 with $n=137$ observations ( 79 boys, 58 girls) includes all children from sample 1 who had not only complete questionnaire, parasitological and clinical data, but also valid shuttle run test results (see also Figure 1).

\section{Discussion}

To our knowledge, this is one of the first attempts to compare objectively measured and self-reported physical fitness in an area where malaria, schistosomiasis and soil-transmitted helminthiasis co-exist [17]. We found a significant association between the cumulative distance covered in a maximal multistage $20 \mathrm{~m}$ shuttle run test by 7-15 year old schoolchildren and the index PF, as calculated from children's answers to 10 questions in a simplified QoL questionnaire. The association between $\mathrm{PF}$ and the children's estimated $\mathrm{VO}_{2}$ max was also statistically significant, regardless of whether uni- or multivariable linear regression analyses were performed. $\mathrm{VO}_{2} \max$ is a widely used proxy for the aerobe capacity, and hence a key indicator for the physical performance of a person [24]. In contrast, the index PR, as calculated from the children's answers on four additional questions in the same simplified QoL questionnaire, was neither associated with cumulative distance nor $\mathrm{VO}_{2}$ max.

The findings that (i) PF was a better predictor than PR for objectively measured physical fitness in the present study and that (ii) the association between PF and cumulative distance was even better than the association between $\mathrm{PF}$ and $\mathrm{VO}_{2}$ max are reasonable. These claims are justified as follows. First, PF literally includes questions about fulfilling distinct physical functions such as running (questions 1 and 2), climbing a hill (questions 4 and 5) or

Table 4 Spearman rank correlation coefficients

\begin{tabular}{lllll}
\hline & Distance & \multicolumn{3}{l}{ VO $_{2}$ max } \\
\cline { 2 - 5 } & Coefficient & p-value & Coefficient & p-value \\
\hline Physical functioning & 0.215 & $0.012^{*}$ & 0.186 & $0.029^{*}$ \\
Physical role & 0.009 & 0.922 & 0.096 & 0.263 \\
\hline
\end{tabular}

* Statistically significant $(\mathrm{p}<0.05)$

Cumulative distance (in $\mathrm{m}$ ) and $\mathrm{VO}_{2} \mathrm{max}$ (in $\mathrm{ml} \mathrm{kg}^{-1} \mathrm{~min}^{-1}$ ) as objectively measured and questionnaire scores on physical functioning (PF) and physical role (PR) as self-reported variables in sample 2 from a study carried out in Grand Moutcho school, Agboville, Côte d'Ivoire, in early 2010 [17]. Sample 2 with $\mathrm{n}=137$ observations ( 79 boys, 58 girls) includes all children with complete questionnaire, parasitological, clinical and shuttle run test results (see also Figure 1). walking (questions 7-9), while PR is more concerned with the physical ability to fulfil certain (social) roles (questions 11-14). Second, three questions (questions 7-9) are directly asking about the ability to cover certain distances (see also Additional file 1: Questionnaire used to assess selfreported physical fitness in the present study).

Interestingly, no association between parasitic infection status and the indices based on self-reported physical fitness was identified. However, by logical deduction, this finding had to be expected after no association was detected between parasitic infections and the objectively measured physical fitness in the umbrella study into which the current investigation was embedded [17] and a strong association was found between the objectively measured physical fitness and self-reported physical fitness in the present study. The finding that the parasitic infection status does not prejudice physical fitness is also in line with some older investigations [27,28], but contradicts newer research [29-31] and the widely held belief that schistosomiasis, soil-transmitted helminthiasis and malaria impair the infected individuals' physical fitness. Some potential explanations and approaches for further research to better understand and solve this discrepancy have been discussed elsewhere [17]. In brief, the participating Ivorian schoolchildren presented with clearly better physical fitness as for example age-matched Canadian counterparts [23]. Differences in life-styles and nutrition might, at least to some degree, explain this observation [32-35]. It has also been implied that the Ivorian children with a parasitic infection could maybe mask the incurred disability by their generally excellent level of physical fitness. The children may adapt quite well to parasitic infections that are acquired early in their life and the children do not yet experience disability caused by advanced chronic disease. Furthermore, it has been suggested that children attending school might not be fully representative in a given epidemiological setting, as children from poorest and furthest away households are less likely to be registered at school and at the same time more likely to be infected with parasites. It is also conceivable that 
Table 5 Uni- and multivariable linear regression models

\begin{tabular}{|c|c|c|c|c|c|c|c|}
\hline \multirow[b]{2}{*}{ Model } & \multirow[b]{2}{*}{ Explanatories } & \multicolumn{3}{|l|}{ Distance } & \multicolumn{3}{|l|}{$\mathrm{VO}_{2} \max$} \\
\hline & & Coefficient & $95 \% \mathrm{Cl}^{\mathrm{a}}$ & $\mathrm{p}$-value & Coefficient & $95 \% \mathrm{Cl}^{\mathrm{a}}$ & $p$-value \\
\hline \multirow[t]{6}{*}{ Univariable } & Physical functioning & 5.13 & $1.12,9.14$ & $0.012^{*}$ & 0.07 & $0.01,0.12$ & $0.017^{*}$ \\
\hline & Physical role & 0.50 & $-1.95,2.96$ & 0.685 & -0.01 & $-0.05,0.02$ & 0.453 \\
\hline & Ambient air temperature & 7.25 & $-11.17,25.67$ & 0.438 & 0.03 & $-0.22,0.28$ & 0.809 \\
\hline & Ambient air humidity & -2.44 & $-10.53,5.66$ & 0.553 & 0.01 & $-0.10,0.12$ & 0.888 \\
\hline & Sex & 358.27 & $255.56,460.98$ & $<0.001^{*}$ & 4.23 & $2.80,5.66$ & $<0.001^{*}$ \\
\hline & Age & 25.14 & $-8.29,58.58$ & 0.139 & -1.13 & $-1.53,-0.72$ & $<0.001^{*}$ \\
\hline \multirow[t]{6}{*}{ Multivariable $^{b, c}$} & Physical functioning & 4.67 & $0.97,8.36$ & $0.014^{*}$ & 0.06 & $0.02,0.11$ & $0.008^{*}$ \\
\hline & Physical role & -0.61 & $-2.86,1.63$ & 0.589 & -0.01 & $-0.04,0.02$ & 0.425 \\
\hline & Ambient air temperature & 36.65 & $-7.34,80.64$ & 0.102 & 0.48 & $-0.06,1.01$ & 0.080 \\
\hline & Ambient air humidity & 10.80 & $-8.61,30.21$ & 0.273 & 0.14 & $-0.10,0.37$ & 0.249 \\
\hline & Sex & 359.28 & $257.96,460.60$ & $<0.001^{*}$ & 4.36 & $3.13,5.60$ & $<0.001^{*}$ \\
\hline & Age & 23.51 & $-5.26,52.29$ & 0.108 & -1.14 & $-1.49,-0.79$ & $<0.001^{*}$ \\
\hline
\end{tabular}

a $95 \%$ confidence interval

${ }^{\mathrm{b}}$ Key indicators of the distance regression model: $\mathrm{F}(6.130)=10.53, \mathrm{p}<0.001, \mathrm{R}^{2}=0.327$

${ }^{c}$ Key indicators of the $\mathrm{VO}_{2}$ max regression model: $\mathrm{F}(6.130)=17.26, \mathrm{p}<0.001, \mathrm{R}^{2}=0.443$

* Statistically significant $(p<0.05)$

Cumulative distance (in $\mathrm{m}$ ) and $\mathrm{VO}_{2} \mathrm{max}$ (in $\mathrm{ml} \mathrm{kg}^{-1} \mathrm{~min}^{-1}$ ) as objectively measured outcome variables and questionnaire scores on physical functioning and physical role as self-reported explanatories in sample 1 from a study carried out in Grand Moutcho school, Agboville, Côte d'lvoire, in early 2010 [17]. Sample 1 with $n=137$ observations ( 79 boys, 58 girls) includes all children with complete questionnaire, parasitological, clinical and shuttle run test results (see also Figure 1). Ambient air temperature (in ${ }^{\circ} \mathrm{C}$ ) and relative humidity (in \%) as well as participants sex (reference: female) and age (in years) were included as potential confounders.

Table 6 Uni- and multivariable linear regression models

\begin{tabular}{|c|c|c|c|c|c|c|c|}
\hline \multirow[b]{3}{*}{ Model } & \multirow[b]{3}{*}{ Explanatories } & \multicolumn{3}{|l|}{ Sample 1} & \multicolumn{3}{|l|}{ Sample 2} \\
\hline & & \multicolumn{3}{|c|}{ Physical functioning } & \multicolumn{3}{|c|}{ Physical functioning } \\
\hline & & Coefficient & $95 \% \mathrm{Cl}^{\mathrm{a}}$ & p-value & Coefficient & $95 \% \mathrm{Cl}^{\mathrm{a}}$ & p-value \\
\hline \multirow[t]{13}{*}{ Univariable } & S. haematobium light infection & -4.01 & $-10.84,2.83$ & 0.249 & -0.24 & $-7.46,6.97$ & 0.947 \\
\hline & S. haematobium heavy infection & -4.47 & $-11.59,2.64$ & 0.216 & -1.39 & $-8.84,6.07$ & 0.713 \\
\hline & S. mansoni light infection & -3.22 & $-8.55,2.10$ & 0.234 & -3.85 & $-9.33,1.63$ & 0.167 \\
\hline & S. mansoni moderate infection & -2.21 & $-8.69,4.26$ & 0.501 & 1.16 & $-5.63,7.94$ & 0.736 \\
\hline & S. mansoni heavy infection & 3.97 & $-13.92,21.85$ & 0.662 & -3.44 & $-23.98,17.09$ & 0.741 \\
\hline & A. lumbricoides light and moderate infection & 3.79 & $-17.81,25.38$ & 0.730 & 2.81 & $-17.59,23.22$ & 0.785 \\
\hline & Hookworm light and moderate infection & 3.15 & $-3.53,9.84$ & 0.353 & 2.08 & $-4.85,9.00$ & 0.554 \\
\hline & Concurrent helminth infections: one & -1.71 & $-9.95,6.53$ & 0.682 & 3.22 & $-5.33,11.76$ & 0.458 \\
\hline & Concurrent helminth infections: two & -4.73 & $-12.64,3.19$ & 0.240 & -1.59 & $-9.73,6.55$ & 0.699 \\
\hline & Concurrent helminth infections: three and more & -0.95 & $-11.76,9.86$ & 0.862 & 3.75 & $-7.29,14.79$ & 0.503 \\
\hline & Plasmodium spp. infection & -1.18 & $-6.60,4.23$ & 0.667 & -1.83 & $-7.30,3.62$ & 0.507 \\
\hline & Sex & 4.13 & $-0.59,8.85$ & 0.086 & 2.37 & $-2.57,7.30$ & 0.345 \\
\hline & Age & -0.13 & $-1.48,1.22$ & 0.849 & -0.05 & $-1.44,1.35$ & 0.948 \\
\hline \multirow[t]{11}{*}{ Multivariable $e^{b, c}$} & S. haematobium light infection & 11.24 & $-34.86,57.35$ & 0.631 & 16.50 & $-27.75,60.75$ & 0.462 \\
\hline & S. haematobium heavy infection & 10.88 & $-35.37,57.13$ & 0.643 & 15.96 & $-28.49,60.40$ & 0.479 \\
\hline & S. mansoni light infection & 14.73 & $-30.72,60.19$ & 0.523 & 19.10 & $-24.10,62.30$ & 0.383 \\
\hline & S. mansoni moderate infection & 17.47 & $-28.19,63.14$ & 0.451 & 25.80 & $-17.61,69.21$ & 0.242 \\
\hline & S. mansoni heavy infection & 23.30 & $-25.63,72.23$ & 0.348 & 21.20 & $-26.58,68.98$ & 0.382 \\
\hline & A. lumbricoides light and moderate infection & 12.51 & $-19.88,44.91$ & 0.447 & 11.80 & $-19.01,42.61$ & 0.450 \\
\hline & Hookworm light and moderate infection & 17.82 & $-26.46,62.09$ & 0.428 & 20.03 & $-21.82,61.89$ & 0.345 \\
\hline & Concurrent helminth infections: one & -13.16 & $-59.73,33.41$ & 0.577 & -13.10 & $-57.89,31.70$ & 0.564 \\
\hline & Concurrent helminth infections: two & -31.47 & $-122.23,59.28$ & 0.494 & -38.70 & $-125.13,47.73$ & 0.377 \\
\hline & Concurrent helminth infections: three and more & -46.00 & $-180.52,88.52$ & 0.500 & -53.39 & $-181.14,74.37$ & 0.410 \\
\hline & Plasmodium spp. infection & -1.21 & $-6.94,4.52$ & 0.678 & -2.05 & $-7.87,3.76$ & 0.486 \\
\hline
\end{tabular}


Table 6 Uni- and multivariable linear regression models (Continued)

\begin{tabular}{ccccccc}
\hline Sex & 3.28 & $-1.82,8.38$ & 0.206 & 2.03 & $-3.25,7.30$ & 0.448 \\
Age & 0.11 & $-1.38,1.60$ & 0.882 & -0.01 & $-1.54,1.53$ & 0.992 \\
\hline
\end{tabular}

a $95 \%$ confidence interval

${ }^{b}$ Key indicators of the regression model based on sample 1: $F(13,153)=0.55, p=0.891, R^{2}=0.045$

${ }^{c}$ Key indicators of the regression model based on sample 2: $F(13,123)=0.66, p=0.797, R^{2}=0.065$

* Statistically significant $(p<0.05)$

Questionnaire scores on physical functioning as self-reported outcomes and helminth and Plasmodium spp. infections (reference: no infection) as parasitologically diagnosed explanatories in samples 1 and 2 from a study carried out in Grand Moutcho school, Agboville, Côte d'lvoire, in early 2010 [17]. Sample 1 with $n=167$ observations ( 97 boys, 70 girls) includes all children with complete questionnaire, parasitological and clinical data. Sample 2 with $n=137$ observations ( 79 boys, 58 girls) includes all children from sample 1 who had not only complete questionnaire, parasitological and clinical data, but also valid shuttle run test results (see also Figure 1). Infection intensities were defined according to WHO guidelines [26]. Categories of explanatories with $\mathrm{n} \leq 1$ observations were combined with the next best category of the same explanatory. Participants sex (reference: female) and age (in years) were included as potential confounders.

children really suffering from the adverse effects of the infections rest at home because of their signs and symptoms, and hence did not take part in our study.

Of particular interest was the fact that the use of a QoL questionnaire, which proofed to be a valid tool to assess the schoolchildren's physical fitness in the respective study area, permitted the inclusion of an additional 30 children who had to be excluded from the shuttle run test due to medical concerns. An attrition analysis indicated that this excluded group of children was not different from the group that could successfully complete the shuttle run test with regard to sex, age or parasitic infection status. However, the mean PF scores of the parasitized and excluded children was considerably lower than the mean PF scores of the children who were parasitized as well but able to participate in the shuttle run test. It could be hypothesized that mainly children who suffer the most from their parasitic infections were excluded from the physical fitness test - precisely because of experiencing severe sequelae. Supposedly due to the relatively small sample size, which was at least partially owed to our rigorous study design, the difference in PF between the two groups showed no statistical significance. As revealed by the analysis of the two different samples in Table 6, the inclusion of the 30 children who were probably most seriously affected by parasitic infections could not overpower the results of the other 137 children. Nevertheless, their inclusion was only possibly thanks to the QoL questionnaire results and their exclusion would have led most likely to biased results.

\section{Conclusion}

We consider the questionnaire employed in the present study as a valid tool to assess schoolchildren's physical fitness in the respective study area. Nevertheless, further validation in other settings of Côte d'Ivoire (e.g. urban areas) and elsewhere in sub-Saharan Africa is warranted. The questionnaire was particularly useful in assessing physical fitness of those children who were unable to complete an exhausting physical fitness test. Future and preferably larger studies to assess disability caused by helminthic infections, other NTDs and malaria should use a test-retest design with intermittent treatment or even piggyback on continuous preventive chemotherapy campaigns. Furthermore, they should also consider dimensions of QoL other than physical fitness, for instance bodily pain and potentially following affection of vitality, mental health and social functioning. However, these dimensions are exceedingly difficult to measure with tools that do not include one or the other form of a questionnaire. This is even more true when affection is subtle as it is often the case with NTDs. We believe that QoL questionnaires will gain further importance in eliciting and quantifying disability caused by NTDs. Hence, further development and validation of such tools, for instance by using mixed methods triangulation approaches, is warranted.

Table 7 Attrition analysis of mean questionnaire scores on self-reported physical functioning (PF)

\begin{tabular}{lllllll}
\hline & \multicolumn{5}{c}{ Sample $\mathbf{2}$} & \multicolumn{3}{c}{ Excluded } \\
\cline { 2 - 7 } Parasitic infection status & $\mathbf{n}$ & mean score PF & $\mathbf{9 5 \%} \mathbf{C l}^{\mathbf{a}}$ & $\mathbf{n}$ & mean score PF & $\mathbf{9 5 \% ~ C l}$ \\
\hline Parasite-free & 15 & 51.7 & $41.3,62.1$ & 3 & 66.7 & $16.5,116.9$ \\
Parasitized & 122 & 52.3 & $49.8,54.8$ & 27 & 44.6 & $37.8,51.5$ \\
All & 137 & 52.2 & $49.7,54.7$ & 30 & 46.8 & $39.9,53.8$ \\
\hline
\end{tabular}

a $95 \%$ confidence interval

Questionnaire scores and parasitological results stem from a study carried out in Grand Moutcho school, Agboville, Côte d'Ivoire, in early 2010 [17]. Sample 2 with $n=137$ observations ( 79 boys, 58 girls) includes all children who had complete questionnaire, parasitological, clinical and also shuttle run test results (see also Figure 1). The group of excluded with $n=30$ observations (18 boys, 12 girls) consists of all children with complete questionnaire, parasitological and clinical data, but no valid shuttle run test results (see also Figure 1). Together, the two groups add up to sample 1 with $n=167$ observations (97 boys, 70 girls), which includes all children with complete questionnaire, parasitological and clinical data, but not necessarily valid shuttle run test results. 


\section{Additional material}

Additional file 1: Questionnaire employed to assess self-reported physical fitness in the present study. Two sections about physical

functioning and physical role from the widely used SF-36v2 questionnaire (Medical Outcome Trust, Boston, MA, USA; Health Assessment Lab, Boston, MA, USA; QualityMetric, Lincoln "RI, USA) [14,18] were used as templates, adapted to the specific study setting, pre-tested and further revised.

\section{Acknowledgements}

We would like to thank Prof. Bassirou Bonfoh, Director General of the Centre Suisse de Recherches Scientifiques en Côte d'Ivoire, Dr. Kouassi B. Crépin Departmental Director of Agboville, and Dr. Akaffou Rofu, Head of Health Services at School and University for their support and facilitation of this study. Many thanks are addressed to Ms. Stefanie J. Krauth, Ms. Katarina Stete, Ms. Aurélie Righetti, Dr. Julie Balen, Mr. Dominik Glinz, Mr. Laurent K. Lohourignon, Mr. Mahamadou Traoré and Mr. Brou Kouakou Jean for their help with field and laboratory work. Furthermore, we are indebted to the primary school teacher team of Grand Moutcho for their excellent cooperation and the schoolchildren for their enthusiastic participation. We are grateful for a series of excellent comments put forth by two anonymous reviewers.

This study received financial support from the Swiss Tropical and Public Health Institute (Teaching \& Training), Fairmed, and the University of Georgia Research Foundation, Inc, which is funded by the Bill and Melinda Gates Foundation for the SCORE project. Thomas Fürst is associated to the National Centre of Competence in Research (NCCR) North-South and grateful for financial support through a Pro*Doc Research Module from the Swiss National Science Foundation (SNSF; project no. PDFMP3-123185). Jürg Utzinger acknowledges also financial support from the SNSF (project no. IZ70Z0_123900). The funders had no role in study design, data collection and analysis, decision to publish or preparation of the manuscript.

\section{Author details}

'Department of Epidemiology and Public Health, Swiss Tropical and Public Health Institute, Basel, Switzerland. ${ }^{2}$ University of Basel, Basel, Switzerland. ${ }^{3}$ Department of Public Health, Institute for Sports and Sports Sciences, University of Basel, Basel, Switzerland. ${ }^{4}$ Centre Suisse de Recherches Scientifiques en Côte d'Ivoire, Abidjan, Côte d'Ivoire. ${ }^{5}$ UFR Biosciences, Université de Cocody-Abidjan, Abidjan, Côte d'Ivoire. ${ }^{6}$ Services de Santé Scolaire et Universitaire, Agboville, Côte d'Ivoire.

\section{Authors' contributions}

TF, IM, JU and EKN designed the study; IM, JTC and AKY implemented the study; TF and IM managed, analysed and interpreted the data; TF, IM and JU wrote the paper. JU and EKN supervised the different phases of the study. All authors read, revised and approved the final manuscript.

\section{Competing interests}

The authors declare that they have no competing interests.

Received: 22 February 2011 Accepted: 24 June 2011

Published: 24 June 2011

\section{References}

1. Global burden of disease study. [http://www.globalburden.org/], accessed: 27 Jan 2011

2. Murray CJL: Rethinking DALYs. In The Global Burden of Disease: A Comprehensive Assessment of Mortality and Disability from Diseases, Injuries, and Risk Factors in 1990 and Projected to 2020. Volume I. Edited by: Murray CJL, Lopez AD. Cambridge: Harvard University Press; 1996:1-99.

3. Gold MR, Stevenson D, Fryback DG: HALYs and QALYs and DALYs, Oh My: similarities and differences in summary measures of population health. Annu Rev Public Health 2002, 23:115-134.

4. Arnesen T, Nord E: The value of DALY life: problems with ethics and validity of disability adjusted life years. BMJ 1999, 319:1423-1425.
5. King $\mathrm{CH}$, Bertino AM: Asymmetries of poverty: why global burden of disease valuations underestimate the burden of neglected tropical diseases. PLoS Negl Trop Dis 2008, 2:e209.

6. Anand S, Hanson K: Disability-adjusted life years: a critical review. J Health Econ 1997, 16:685-702.

7. Reidpath DD, Allotey PA, Kouame A, Cummins RA: Measuring health in a vacuum: examining the disability weight of the DALY. Health Policy Plan 2003, 18:351-356.

8. Garratt A, Schmidt L, Mackintosh A, Fitzpatrick R: Quality of life measurement: bibliographic study of patient assessed health outcome measures. BMJ 2002, 324:1417-1421.

9. Jia TW, Zhou XN, Wang XH, Utzinger J, Steinmann P, Wu XH: Assessment of the age-specific disability weight of chronic schistosomiasis japonica. Bull World Health Organ 2007, 85:458-465.

10. Jia TW, Utzinger J, Deng Y, Yang K, Li YY, Zhu JH, King CH, Zhou XN: Quantifying quality of life and disability of patients with advanced schistosomiasis japonica. PLoS Negl Trop Dis 2011, 5:e966.

11. Ziegelbauer K, Steinmann P, Zhou H, Du ZW, Jiang JY, Fürst T, Jia TW, Zhou XN, Utzinger J: Self-rated quality of life and school performance in relation to helminth infections: case study from Yunnan, People's Republic of China. Parasit Vectors 2010, 3:61

12. King $\mathrm{CH}$, Dangerfield-Cha $\mathrm{M}$ : The unacknowledged impact of chronic schistosomiasis. Chronic IIIn 2008, 4:65-79.

13. Schistosomiasis Consortium for Operational Research and Evaluation (SCORE): Subtle morbidity cohort studies. [http://score.uga.edu/Subtle. Morbidity.html], accessed: 27 Jan 2011

14. SF-36v2 health survey. [http://www.sf-36.org/tools/pdf/SF36v2_Standard_Sample.pdf], accessed: 27 Jan 2011.

15. EQ-5D-5L. [http://www.eurogol.org/fileadmin/user_upload/Documenten/ PDF/Languages/Sample_UK__English_EQ-5D-5L.pdf], accessed: 27 Jan 2011.

16. The World Health Organization Quality of Life (WHOQOL)-bref. [http:// www.who.int/substance_abuse/research_tools/en/english_whogol.pdf], accessed: 27 Jan 2011.

17. Müller I, Coulibaly JT, Fürst T, Knopp S, Hattendorf J, Krauth SJ, Stete K, Righetti AA, Glinz D, Yao AK, et al: Effect of schistosomiasis and soiltransmitted helminth infections on physical fitness of school children in Côte d'Ivoire. PLoS Negl Trop Dis 2011, 5:e1239.

18. SF-36v2 health survey. [http://www.qualitymetric.com/WhatWeDo/ GenericHealthSurveys/SF36v2HealthSurvey/tabid/185/Default.aspx], accessed: 27 Jan 2011.

19. Katz N, Chaves A, Pellegrino J: A simple device for quantitative stool thick-smear technique in schistosomiasis mansoni. Rev Inst Med Trop São Paulo 1972, 14:397-400.

20. World Health Organization: Helminth Control in School-aged Children: A Guide for Managers of Control Programmes Geneva: WHO; 2002.

21. Savioli L, Hatz C, Dixon H, Kisumku UM, Mott KE: Control of morbidity due to Schistosoma haematobium on Pemba Island: egg excretion and hematuria as indicators of infection. Am J Trop Med Hyg 1990, 43:289-295.

22. Kent AR, Elsing SH, Hebert RL: Conjunctival vasculature in the assessment of anemia. Ophthalmology 2000, 107:274-277.

23. Léger LA, Mercier D, Gadoury C, Lambert J: The multistage 20 metre shuttle run test for aerobic fitness. J Sports Sci 1988, 6:93-101.

24. American College of Sports Medicine: ACSM's Guidelines for Exercise Testing and Prescription Philadelphia: Lippincott Williams \& Wilkins; 2008.

25. Ware JE, Kosinski M, Turner-Bowker DM, Gandek B: User's Manual for the SF12v2 Health Survey Lincoln: QualityMetric; 2007.

26. World Health Organization: Prevention and control of schistosomiasis and soil-transmitted helminthiasis: report of a WHO expert committee. WHO Tech Rep Ser 2002, 912:1-57.

27. Davies $C T$ : The effects of schistosomiasis, anaemia and malnutrition on the responses to exercise in African children. J Physiol 1973, 230(Suppl):27.

28. Walker AR, Walker BF, Richardson BD, Smit PJ: Running performance in South African Bantu children with schistosomiasis. Trop Geogr Med 1972 24:347-352.

29. Kvalsvig JD: The effects of schistosomiasis haematobium on the activity of school children. J Trop Med Hyg 1986, 89:85-90.

30. Ndamba J, Makaza N, Munjoma M, Gomo E, Kaondera KC: The physical fitness and work performance of agricultural workers infected with 
Schistosoma mansoni in Zimbabwe. Ann Trop Med Parasitol 1993, 87:553-561.

31. King CH, Dickman K, Tisch DJ: Reassessment of the cost of chronic helmintic infection: a meta-analysis of disability-related outcomes in endemic schistosomiasis. Lancet 2005, 365:1561-1569.

32. Brown T, Bell M: Off the couch and on the move: global public health and the medicalisation of nature. Soc Sci Med 2007, 64:1343-1354.

33. Mitchikpe CE, Dossa RA, Ategbo EA, Van Raaij JM, Kok FJ: Seasonal variation in food pattern but not in energy and nutrient intakes of rural Beninese school-aged children. Public Health Nutr 2009, 12:414-422.

34. Choi BC, Hunter DJ, Tsou W, Sainsbury P: Diseases of comfort: primary cause of death in the 22nd century. J Epidemiol Community Health 2005, 59:1030-1034.

35. Ezzati M, Lopez AD, Rodgers A, Vander Hoorn S, Murray CL: Selected major risk factors and global and regional burden of disease. Lancet 2002, 360:1347-1360.

doi:10.1186/1756-3305-4-116

Cite this article as: Fürst et al:: Questionnaire-based approach to assess schoolchildren's physical fitness and its potential role in exploring the putative impact of helminth and Plasmodium spp. infections in Côte d'Ivoire. Parasites \& Vectors 2011 4:116.

\section{Submit your next manuscript to BioMed Central} and take full advantage of:

- Convenient online submission

- Thorough peer review

- No space constraints or color figure charges

- Immediate publication on acceptance

- Inclusion in PubMed, CAS, Scopus and Google Scholar

- Research which is freely available for redistribution

Submit your manuscript at www.biomedcentral.com/submit
C Biomed Central 